\title{
ENSINO REMOTO NA PANDEMIA: DIFICULDADES E APRENDIZADOS
}

\section{REMOTE TEACHING IN PANDEMIA: DIFFICULTIES AND LEARNING}

Camila Martins Vellar

\author{
Licenciada em Letras-Português e discente do curso de Bacharelado em Redação \\ e Revisão de Textos pela Universidade Federal de Pelotas, Brasil. \\ E-mail: camilamartinsvellar@gmail.com
}

Recebido: 31/03/2021- Aceito: 31/03/2021

\section{Resumo}

Este trabalho visa a verificar quais as principais dificuldades enfrentadas na implantação emergencial do processo de ensino e de aprendizagem remoto no ensino básico da rede pública e quais aprendizados ficarão para o retorno do ensino presencial, conforme pesquisas atuais. Partese da hipótese de que boa parte dos professores e dos estudantes da rede básica pública não tinham familiaridade com as TIC - Tecnologias de Informação e Comunicação - nas suas aulas regulares. Em virtude disso, acredita-se que tiveram dificuldades na aplicação dessas ferramentas de modo emergencial no ensino remoto como sendo a única alternativa, devido à pandemia de covid-19, que era inesperada por todos. Acredita-se também que, no retorno ao ensino presencial pós-pandemia, muitas das ferramentas utilizadas no ensino remoto permanecerão sendo utilizadas e contribuirão no processo de ensino e de aprendizagem.

Palavras-chave: Dificuldades; Ensino remoto; Pandemia.

\section{Abstract}

This work aims to verify which are the main difficulties faced in the emergency implantation of the remote teaching-learning process in the basic education of the public network and which learnings will be for the return of the face-to-face classes, according to current research. It starts with the hypothesis that a good part of the teachers and students of public basic education were not familiar with ICT - Information and Communication Technologies - in their regular classes. As a result, it is believed that they had difficulties in applying these tools on an emergency basis in remote education as the only alternative, due to the covid-19 pandemic, which was unexpected by everyone. It is also believed that, when returning to post-pandemic classroom teaching, many of the tools used in remote education will continue to be used and will contribute to the teaching and learning process.

Keywords: Difficulties; Remote teaching; Pandemic. 


\section{Introdução}

O ensino básico era tradicionalmente presencial, exceto em casos de hospitalização por longos períodos ou doenças que impedem o aluno de frequentar o ambiente escolar, nos quais a educação a distância é prevista por lei para que a continuação da aprendizagem não seja prejudicada. Nesse sentido, os professores da rede básica, principalmente a pública, no geral, não estavam habituados a utilizar ferramentas de ensino remoto - tanto em virtude de não-familiaridade com as mesmas, como em decorrência de que alguns alunos não têm as ferramentas de acesso ou as escolas não dispõem de recursos suficientes.

Em março de 2020, com a pandemia do novo coronavírus, o ERE - Ensino Remoto Emergencial - surgiu de modo imprevisto e urgente na rede básica de ensino, para que, assim, os educandos não perdessem o vínculo com a escola durante o período de isolamento social, o qual se apresentou como o único meio de combater a proliferação da covid-19. Desse modo, os professores se viram obrigados a se adaptar a novas possibilidades de ensino-aprendizagem, utilizando as Tecnologias da Informação e da Comunicação como aliadas nesse processo.

Nesse cenário, este trabalho de pesquisa visa a verificar, através de pesquisa bibliográfica, quais foram as principais dificuldades nessa adaptação, quais fatores permitiram/facilitaram a aplicação dessa modalidade e quais aprendizados desse momento poderão permanecer sendo utilizados nas aulas presenciais pós-pandemia, buscando melhorar a relação ensino-aprendizagem.

Através da leitura de desabafos em grupos virtuais e assistindo entrevistas, conversando com professores, percebe-se que boa parte dos professores e dos estudantes da rede básica de ensino público não tinham familiaridade com as TIC Tecnologias de Informação e Comunicação - nas suas aulas regulares. Em virtude disso, acredita-se que tiveram dificuldades na aplicação dessas ferramentas de modo emergencial no ensino remoto como sendo a única alternativa, devido à pandemia de covid-19, que era inesperada por todos. 
Acredita-se também que, no retorno ao ensino presencial pós-pandemia, muitas das ferramentas utilizadas no ensino remoto permanecerão seguir sendo utilizadas e contribuirão para o processo de ensino e aprendizagem, considerando que a maioria estará adaptada ao seu uso.

Nesse contexto, a metodologia utilizada consiste numa abordagem qualitativa de natureza exploratória, baseada em um procedimento de revisão bibliográfica e documental, analisando artigos recentes acerca do trabalho dos professores da rede básica, no ensino remoto emergencial. Busca-se verificar quais os maiores empecilhos para implantação dessa modalidade, quais fatores permitiram/facilitaram a aplicação dessa modalidade e quais aprendizados ficarão para o retorno presencial pós-pandemia, apontados na bibliografia analisada.

\section{Revisão Bibliográfica}

Consoante a Moreira, Henriques e Barros (2020), as tecnologias e as redes de comunicação têm evoluído e, consequentemente, provocado modificações na vida de todos. Dessa maneira, o cenário da educação também vem se modificando, com o surgimento de novas formas de ensino-aprendizagem. Nesse sentido, Carlos et al (2017), mencionam a pesquisa "TIC Educação", segundo a qual aproximadamente $91 \%$ dos estudantes possuem algum tipo de dispositivo móvel. Isso fortalece o uso das TIC na educação, podendo ser uma ferramenta auxiliar no processo de ensino-aprendizagem. Entretanto, os autores destacam que ninguém imaginaria que seria preciso uma mudança tão rápida e emergencial de modo obrigatório no ensino, por causa da expansão da pandemia de covid-19.

Nascimento, Ramos, Melo e Castioni (2020) ressaltam que a pandemia de corona-vírus suspendeu as aulas presenciais em todos os níveis e modalidades de ensino no Brasil - da creche ao ensino superior. Para que o ano não ficasse perdido, o ensino emergencial de modo remoto aparece como principal alternativa, entretanto isso envolve letramento digital, formação continuada e várias maneiras de adaptação pedagógica para que seja implantado emergencialmente, conforme ressaltam os autores supracitados. 
Com o avanço inesperado do vírus, todas as instituições educacionais precisaram cancelar os afazeres presenciais, como sendo a única alternativa para tentar conter o crescimento dos índices de contágio. Então, as aulas de maneira remota foram adotadas por quase todas as instituições como alternativa para que a rotina de aquisição do conhecimento não permanecesse suspensa junto com as aulas presenciais. Conforme Carlos et al (2017), para fazer a utilização das TIC Tecnologias de Informação e Comunicação - na metodologia de ensino, há uma infinidade de recursos tecnológicos disponíveis. Homens e máquinas interagem diariamente, no entanto, o ensino de modo remoto surge como uma prática emergente, de acordo com os autores.

No entanto, essa mudança brusca no processo de ensino acabou forçando os professores a adotar práticas muito distintas das práticas da educação digital em rede de qualidade, conforme apontam Moreira, Henriques e Barros (2020). Assim, muitos professores - até mesmo os que já trabalhavam com as TIC no cotidiano escolar antes da pandemia - se viram perdidos nessa nova forma de ensino. Os autores destacam que, na transposição de metodologias e práticas pedagógicas físicas para a modalidade remota emergencial, os professores se transformaram em youtubers, aprendendo a usar sistemas de gravação de vídeos e/ou sistemas de videoconferência e plataformas de aprendizagem.

O problema ressaltado por Moreira, Henriques e Barros (2020) é que, devido à necessidade de cursos de formação continuada e de preparo dos professores, as tecnologias acabam sendo utilizadas de modo instrumental, em um ensino transmissivo. Os autores enfatizam que além de transferir práticas presenciais, é urgente que se criem modelos de aprendizagem virtuais e que sejam incorporados ambientes de aprendizagem construtivos nos sistemas utilizados. Assim, é imprescindível que os profissionais tenham uma permanente formação a respeito do uso das TICs no ensino, para que não transponham métodos tradicionais sem usufruir adequadamente das tecnologias como aliadas nesse processo. 


\section{Revista Multidisciplinar do Nordeste Mineiro, v.1, $2021 / 01$ \\ ISSN 2178-6925}

informações sobre as atividades online que devem realizar, dentro e fora da plataforma, individualmente ou em grupo, exatamente como num ambiente de sala de aula física. (MOREIRA, HENRIQUES E BARROS, p. 357, 2020).

Assim, é válido ressaltar que atividades desenvolvidas de modo remoto ou no ensino a distância, quando bem planejadas e empregadas, podem favorecer uma aprendizagem produtiva. Para isso, a utilização das TICs adequadas é fundamental. Em conformidade com Salmon (2004), as e-atividades se baseiam na concepção, segundo a qual o conhecimento é construído pelos alunos de maneira colaborativa, ativa e participativa - sendo, assim, essencial para partilhar o conhecimento construído.

Moreira, Henriques e Barros (2020) apontam alguns critérios importantes para elaboração das atividades virtuais baseadas em uma perspectiva integradora e construtora de metodologias de ensino e de aprendizagem, as quais são:

Promover no estudante um papel ativo.

Ajudar o estudante a elaborar seu próprio conhecimento a partir da interação com outras pessoas (estudantes e professor) e recursos (digitais).

Promover a formulação de questões que podem estar sujeitas a investigação.

Convidar a expressar, organizar e contrastar o conhecimento e a hipótese inicial dos alunos sobre os objetos de estudo a serem investigados.

Estimular a aprendizagem autônoma.

Promover o desenvolvimento de projetos de pesquisa para responder a problemas.

Promover a exploração de novos conteúdos através de recursos digitais e outras fontes de informação.

Estruturar as informações obtidas, incluindo tarefas como resumir, entender, relacionar, concluir, etc.

Estimular a comunicação, discussão ou colaboração com outros participantes no espaço de aprendizagem virtual.

Promover a aplicação ou transferência de processos cognitivos em novos cenários e contextos.

Refletir de forma meta-cognitiva sobre o desenvolvimento e os resultados da pesquisa realizada.

(MOREIRA, HENRIQUES E BARROS, p. 358, 2020)

Desse modo, os autores ressaltam, ainda, que a e-atividade precisa ser bem estruturada para ser motivadora, envolvente e intencional, sendo capaz de 
oportunizar uma aprendizagem ativa e desenvolver as competências e habilidades indispensáveis ao aluno. Ainda conforme os autores,

A estratégia didática em que se assenta o desenvolvimento da eatividade, deverá apontar no sentido de conseguir que um grupo seja uma verdadeira comunidade virtual de aprendizagem interativa, colaborativa e investigativa. Deve-se, pois, em salas de aula virtuais, socializar o grupo, induzir e moderar a negociação e a partilha de ideias, facilitar 0 acesso à informação $e$ ao conhecimento e auxiliar no processo de investigação e desenvolvimento do pensamento crítico. (MOREIRA, HENRIQUES E BARROS, p. 360, 2020)

Dessa forma, essa transformação emergencial nas metodologias educacionais requer formação dos profissionais envolvidos, possibilitando meios de apropriação digital desses. Não basta colocar o ensino remoto como um substituto do ensino presencial, mesmo que somente em situação emergencial, sem habilitar os professores para trabalhar nessa modalidade, Moreira, Henriques e Barros (2020) destacam que é necessário que sejam definidas políticas e sejam criados programas de formação e capacitação dos professores e demais funcionários que atuam na educação para que haja uma educação digital de qualidade.

Nesse contexto, conforme Nascimento, Ramos, Melo e Castioni (2020), há uma parcela significativa dos alunos principalmente do ensino público que não dispõem dos recursos mínimos necessários para acompanhar atividades da modalidade remota de ensino - falta de equipamentos, falta de internet, ausência de sinal de TV e formas de garantir a permanência dos estudantes no ano escolar são algumas das dificuldades apontadas pelos autores. Nesse sentido, isso precisa ser analisado e políticas públicas são necessárias, visto que

A dificuldade em estudar durante o período da pandemia pode ser uma fonte de ampliação da desigualdade no futuro. Estudantes que não puderam estudar durante esse período estariam em desvantagem em relação àqueles que puderam ter acesso ao ensino remoto. As consequências negativas do afastamento das 
escolas podem ser ampliadas uma vez que, os estudantes mais afetados são aqueles que já se encontram em desvantagens de oportunidades por conta de condições econômicas e sociais piores do que as de alunos com acesso ao ensino remoto. (NASCIMENTO, RAMOS, MELO E CASTIONI, p. 16, 2020)

Assim, conforme Alves (2020), esses desafios precisam ser vencidos, para que os estudantes tenham acesso e possam interagir com os artefatos culturais e tecnológicos. A autora ressalta que esse cenário de dificuldades relacionadas ao uso das TICs vem rondando a história da educação há décadas e, este ano, em função da pandemia que se instaurou no mundo, evidenciou-se a precisão de utilizá-las emergencialmente para que o processo de ensino-aprendizagem não fosse suspenso por um longo período.

Joye, Moreira e Rocha (2020) destacam, nesse sentido, que o processo de escolarização não poderia ficar parado enquanto perdurasse a pandemia, no entanto os professores e famílias questionam acerca da possibilidade de atender todos alunos garantindo a equidade e a qualidade, visto que muitos não têm acesso a recursos digitais. Conforme a disponibilidade de ferramentas ao aluno, as TICs podem servir como meios a fim de que as tarefas ocorram remotamente, entretanto, para alguns estudantes, esses recursos são inimagináveis em virtude do cenário desigual que assola o país.

Além disso, as autoras supracitadas lembram de que as leis brasileiras tratam da viabilidade da ocorrência de ensino em caráter EaD no ensino básico em casos de emergência. No entanto, as autoras ressaltam que esse ensino remoto através de lives, homeschooling, educação mediada por TIC, não se configura por Educação a Distância. Há uma confusão nos conceitos e muita gente acaba denominando o ensino emergencial remoto de EaD, mas há autores que optam por denominar como "Educação Remota Emergencial", considerando a ausência de um suporte adequado para se caracterizar como EaD. Nessa perspectiva, elas apontam que "remoto" faz referência somente à transformação do espaço físico para o remoto, já na modalidade EaD o processo é compartilhado por vários 
profissionais, como professor conteudista, produtor multimídia, ilustrador, gestor de Ambiente Virtual de Aprendizagem, além de outros envolvidos.

$\mathrm{Na}$ maioria dos casos, nesse ensino remoto emergencial, o professor é o único responsável por todo o encadeamento da relação ensino-aprendizagem. É ele quem seleciona os materiais, cria vídeo-aulas, salas de web-conferência, elabora materiais visualmente atrativos, corrige atividades, dentre outras tarefas. Entretanto, muitos não receberam o devido preparo para isso, visto que essa mudança ocorreu abruptamente.

Joye, Moreira e Rocha (2020) apontam também que o tipo do estudante da EaD é distinto do perfil do ensino remoto - o aluno da modalidade EaD geralmente é um adulto que tem uma motivação para estudar nessa modalidade, já o aluno do ensino remoto emergencial não estava preparado para estudar nessa modalidade nova, inesperada. Outro ponto apontado pelas pesquisadoras é o fato de que nesse ensino remoto emergencial a maioria dos alunos são jovens (crianças ou adolescentes), os quais estão em uma faixa etária que precisa do convívio para aprender a viver em sociedade. Então, em decorrência da falta desse convívio, problemas de caráter psicológico e social podem surgir.

Consoante a análise dessas pesquisadoras,

No Brasil, o corpo docente parte para o improviso usando redes sociais, fazendo uma produção ineficiente de videoaulas postadas no YouTube; enviando atividades previamente selecionadas dos livros didáticos enviadas através de grupos de WhatsApp, criados pelas gestões escolares; fazendo videoconferências utilizando aplicativos como o Google Meet ou o Zoom Meeting, entre outros, ou recorrendo às redes sociais como YouTube e Instagram, as quais, às vezes, nem sempre são muito eficazes, mas que, neste momento, estão sendo o caminho adotado haja vista o celular está substituindo o computador como objeto de acesso a internet no contexto local. Em meio à angústia de cumprir o currículo escolar, as escolas privadas e públicas tentam, de alguma forma, enviar os conteúdos e as atividades se utilizando, como já dito, de e-mails e/ou redes sociais, como Facebook e WhatsApp, bem como aulas ao vivo por meio de videoconferência no horário das aulas presenciais. Outra alternativa tem sido a curadoria, ou seja, a seleção de conteúdos escolares em sites, uma forma de atenuar a evasão escolar que já possuía números elevados mesmo antes da 


\begin{abstract}
pandemia tanto no ensino presencial quanto a distância. As estratégias são variadas haja vista a diferença entre as realidades. Por exemplo, o estado do Amazonas, por sua extensão territorial, já adota a televisão educativa bem antes da pandemia. Já o estado de São Paulo, centro econômico e epicentro da pandemia aqui no Brasil, optou por fazer parcerias com grandes empresas, como a Google, para o uso de aplicativos como Google Classroom, além de parcerias para a oferta de televisão educativa. (JOYE, MOREIRA e ROCHA, p. 20, 2020)
\end{abstract}

Com a difusão dos dispositivos móveis, Carlos et al (2017) enfatizam que propicia-se a aplicação de novas tecnologias como aliadas da prática docente, visto que, em certos casos, faltam laboratórios adequados e a experimentação remota como ferramenta de ensino pode suprir essa necessidade, por exemplo. Assim, os autores supracitados salientam que a proposta de união da tecnologia com a educação, com apoio dos meios móveis que estão amplamente expandidos na sociedade, proporciona uma vasta propagação de conteúdos, considerando a facilidade para acessar os recursos.

Diante do cenário pandêmico, apesar das dificuldades e dos desafios mencionados, é imprescindível que os estudantes não percam o vínculo com a escola nesse momento de isolamento social. A interação entre professor-aluno nesse período e crucial, segundo Joye, Moreira e Rocha (2020), e o investimento por parte do governo para conter a desigualdade social relacionada à viabilidade de uso das tecnologias é algo extremamente necessário.

\title{
Análise dos dados
}

Conforme os autores estudados, há pontos positivos da utilização das TICs na educação, que podem ser aproveitados no retorno às aulas presenciais, mas há também pontos negativos, que fazem com que alguns alunos estejam sendo prejudicados nas aulas remotas. Dessa maneira, foi elaborada o seguinte quadro, com os principais pontos apontados pelos autores, em conformidade com os objetivos deste trabalho: 
Tabela 1: Síntese do levantamento bibliográfico

\begin{tabular}{|c|c|c|}
\hline AUTOR(ES) & $\begin{array}{l}\text { PRINCIPAIS } \\
\text { DIFICULDADES } \\
\text { COM O ENSINO } \\
\text { REMOTO }\end{array}$ & $\begin{array}{lr}\text { FATORES QUE } \\
\text { FACILITARAM A } \\
\text { APLICAÇÃO } \\
\text { DESSA } \\
\text { MODALIDADE E } \\
\text { EDUCAÇÃO PÓS } \\
\text { PANDEMIA }\end{array}$ \\
\hline Carlos et al (2017) & $\begin{array}{l}\text { O fato de que a } \\
\text { mudança foi } \\
\text { rápida demais, } \\
\text { devido ao caráter } \\
\text { emergencial. }\end{array}$ & $\begin{array}{lr}\text { Parte significativa } \\
\text { dos estudantes } \\
\text { possuem algum } \\
\text { tipo de dispositivo } \\
\text { móvel. }\end{array}$ \\
\hline $\begin{array}{l}\text { Nascimento, } \\
\text { Ramos, Melo } \\
\text { Castioni (2020) }\end{array}$ & $\begin{array}{lr}\text { A falta } & \text { de } \\
\text { letramento } & \text { digital, } \\
\text { formação } & \\
\text { continuada } & \text { dos } \\
\text { professores } & \text { acerca } \\
\text { das } & \text { várias } \\
\text { maneiras } & \text { de } \\
\text { adaptação } & \\
\text { pedagógica } & \text { para } \\
\text { essa } & \text { nova } \\
\text { modalidade. } & \end{array}$ & $\begin{array}{lr}\text { A existência de } \\
\text { uma infinidade de } \\
\text { recursos } \\
\text { tecnológicos e a } \\
\text { interação } \\
\text { homens entre } \\
\text { máquinas facilita a } \\
\text { utilização } \\
\text { TICs. }\end{array}$ \\
\hline $\begin{array}{l}\text { Moreira, Henriques } \\
\text { e Barros (2020) }\end{array}$ & $\begin{array}{lr}\text { Devido à falta de } & \text { e } \\
\text { formação } & \text { e } \\
\text { preparo } & \text { dos } \\
\text { professores, as } & \text { acnologias } \\
\text { tecnom } & \\
\text { acabam } & \text { sendo } \\
\text { utilizadas de } & \text { modo } \\
\text { instrumental, em } & \text { ensino } \\
\text { um } & \text { enansmissivo. }\end{array}$ & $\begin{array}{l}\text { As atividades } \\
\text { remotas, quando } \\
\text { bem planejadas e } \\
\text { empregadas, } \\
\text { podem favorecer } \\
\text { uma aprendizagem } \\
\text { produtiva. } \\
\text { A criação de } \\
\text { modelos } \\
\text { aprendizagem que } \\
\text { sejam } \\
\text { incorporados aos } \\
\text { ambientes } \\
\text { aprendizagem de } \\
\text { construtivos nos } \\
\text { sistemas utilizados. }\end{array}$ \\
\hline $\begin{array}{l}\text { Moreira, Henriques } \\
\text { e Barros (2020) }\end{array}$ & $\begin{array}{lr}\text { A existência de } \\
\text { uma parcela } \\
\text { significativa dos } \\
\text { alunos } \\
\text { principalmente do } \\
\text { ensino público que }\end{array}$ & $\begin{array}{lr}\text { Incentivo } & \text { à } \\
\text { formação } & \text { e } \\
\text { capacitação } & \text { dos } \\
\text { profissionais } & \text { da } \\
\text { educação para que } & \\
\text { haja } & \text { uma }\end{array}$ \\
\hline
\end{tabular}




\begin{tabular}{|c|c|c|}
\hline & $\begin{array}{l}\text { não dispõem dos } \\
\text { recursos mínimos } \\
\text { necessários. }\end{array}$ & $\begin{array}{l}\text { educação digital de } \\
\text { qualidade aliada ao } \\
\text { ensino presencial. }\end{array}$ \\
\hline $\begin{array}{l}\text { Joye, Moreira e } \\
\text { Rocha }(2020)\end{array}$ & $\begin{array}{l}\text { Conseguir atender } \\
\text { todos alunos de } \\
\text { forma igualitária e } \\
\text { com qualidade. }\end{array}$ & $\begin{array}{l}\text { As TIC podem } \\
\text { servir como canais } \\
\text { para que as } \\
\text { atividades ocorram } \\
\text { no ensino remoto. }\end{array}$ \\
\hline $\begin{array}{l}\text { Saraiva, Traversini } \\
\text { e Lokmann (2020) }\end{array}$ & $\begin{array}{lr}\text { Desigualdade } & \text { e } \\
\text { Modalidade } & \text { de } \\
\text { ensino nova e } \\
\text { experimental tanto } \\
\text { para professores } \\
\text { como para os } \\
\text { alunos. }\end{array}$ & $\begin{array}{lr}\text { Facilidade } & \text { de } \\
\text { acesso } & \text { aos } \\
\text { recursos } & \\
\text { tecnológicos. } & \\
\text { Educação } & \\
\text { inovadora } & \text { pós } \\
\text { pandemia. } & \\
\end{array}$ \\
\hline $\begin{array}{l}\text { Valente et all } \\
(2020)\end{array}$ & $\begin{array}{lr}\text { Falta de } & \text { suporte } \\
\text { tecnológico } & \text { dos } \\
\text { alunos } & \text { para } \\
\text { acompanhar } & \text { as } \\
\text { atividades. } & \end{array}$ & $\begin{array}{l}\text { Caminhos abertos } \\
\text { para ação criativa } \\
\text { na preparação das } \\
\text { aulas. Grande } \\
\text { maioria dos alunos } \\
\text { domina as } \\
\text { tecnologias } \\
\text { podem as á-la } \\
\text { como aliada na } \\
\text { aprendizagem. }\end{array}$ \\
\hline $\begin{array}{l}\text { Appenzeller et all } \\
(2020)\end{array}$ & $\begin{array}{ll}\text { Instabilidade } & \text { na } \\
\text { conexão } & \text { de } \\
\text { internet. } & \\
\end{array}$ & \\
\hline Silva (2006) & $\begin{array}{l}\text { Dificuldade } \\
\text { docente } \\
\text { relação ao uso das } \\
\text { plataformas } \\
\text { ensino remoto. }\end{array}$ & $\begin{array}{l}\text { Redução de custos } \\
\text { que existem com } \\
\text { ensino presencial. } \\
\text { A utilização de } \\
\text { novas formas de } \\
\text { ensino e } \\
\text { aprendizagem por } \\
\text { meio da tecnologia. }\end{array}$ \\
\hline $\begin{array}{l}\text { Oliveira, Silva e } \\
\text { Silva }(2020)\end{array}$ & $\begin{array}{l}\text { Desafio } \\
\text { professores } \\
\text { ressignificar } \\
\text { atualizar } \\
\text { processo } \\
\text { ensino. }\end{array}$ & $\begin{array}{l}\text { Espera-se que as } \\
\text { vivências } \\
\text { experiências do } \\
\text { ensino remoto } \\
\text { possam servir de } \\
\text { moter para } \\
\text { transformações na } \\
\text { educação básica. }\end{array}$ \\
\hline
\end{tabular}

Elaboração da autora. 
Analisando os pontos apresentados pelos autores, no decorrer da pesquisa bibliográfica, nota-se que uma das principais barreiras referentes ao ensino remoto é em relação à dificuldade de acesso à internet e aos meios tecnológicos que permitam a participação nas atividades escolares remotas. Há uma parcela significativa de alunos que possuem as ferramentas e internet para tal, mas também há uma parcela que não tem a oportunidade de usufruir desses meios.

Assim como entre os professores há dificuldades para utilização das ferramentas de ensino remoto, visto que não tinham familiaridade com as mesmas. Muitos professores já utilizavam algumas plataformas, mas não como um meio único para o processo de ensino-aprendizagem, então até estes tiveram dificuldade para se adaptar a essa mudança radical.

Nesse sentido, os autores pesquisados apontam que a familiaridade com a utilização das tecnologias poderá proporcionar uma inovação no ensino tradicional no retorno as aulas presenciais, já que professores e alunos, em sua maioria, já estarão adaptados a essas ferramentas.

\section{Considerações Finais}

Portanto, na busca, através de pesquisa bibliográfica, acerca das principais dificuldades enfrentadas pela comunidade escolar em relação ao uso das TIC no ensino remoto, identificou-se que as principais dificuldades foram com relação à desigualdade social dos alunos e a falta de formação dos professores em relação ao uso das tecnologias no ensino remoto.

Muitos alunos têm acesso à internet, fato que facilitou a implantação do ensino remoto; mas muitos não o têm, precisando assim de materiais impressos para conseguir realizar as atividades, não podendo assistir à vídeo-aulas ou encontros síncronos, bem como ouvir áudios com explicações ou, até mesmo, tirar suas dúvidas em tempo real com o professor, como acontece virtualmente. Há também os casos dos que possuem um único computador ou smartphone em casa e pais e irmãos precisam utilizar o mesmo, o que atrapalha o processo de aprendizagem. 
Revista Multidisciplinar do Nordeste Mineiro, v.1,

Além disso, muitos professores, até mesmo os mais jovens e acostumados com a utilização das tecnologias encontraram dificuldades na aplicação emergencial do ensino remoto, porque é uma modalidade que precisou ser colocada em uso de uma semana para outra, pegando todos despreparados. Escolher plataformas ou, inclusive, redes sociais para envio e recebimento das atividades, gravar vídeoaulas, tudo envolve um replanejamento pedagógico para o qual ninguém estava preparado.

Desse modo, verificou-se que os autores pesquisados consideram a possibilidade de incentivo à utilização das TIC no retorno ao ensino presencial póspandemia, visto que todos envolvidos acabaram obrigatoriamente se adaptando a essa nova forma de aprender e de ensinar. Muitos professores buscaram por sua conta cursos de formação continuada para explorar melhor a nova modalidade de ensino, bem como algumas redes de ensino, como estados e prefeituras, oportunizaram aos professores cursos, semanas de formação acerca dessa temática, para facilitar a adaptação, além de criação de programas de apoio tecnológico aos alunos sem os recursos mínimos necessários. Assim, no póspandemia, provavelmente isso tudo terá sido um passo para inovar o ensino básico público, especialmente.

\section{Referências}

ALVES. L. Educação remota: entre a ilusão e a realidade. Fluxo Contínuo. V.8, N.3, 2020.

APPENZELLER, S.; MENEZES, F. H.; SANTOS, G. G.; PADILHA, R. F.; GRAÇA, H. S.; BRAGANÇA, J. F. Novos Tempos, Novos Desafios: Estratégias para Equidade de Acesso ao Ensino Remoto Emergencial. Revista Brasileira De Educação Médica, 44 (Sup.1): E0155, 2020. Disponível em: https://doi.org/10.1590/1981-5271v44.supl.1-20200420. Acesso em 28 de outubro de 2020.

CARLOS, L. M. et all. Estratégias de Integração de Tecnologia no Ensino: Uma Solução Baseada em Experimentação Remota Móvel. Disponível em:https://www.researchgate.net/publication/319662142_Estrategias_de_Integraca o_de_Tecnologia_no_Ensino_Uma_Solucao_Baseada_em_Experimentacao_Remo ta_Movel?enrichld=rgreq-c5098f4618e1979909c0717009b7a7e7-

XXXX\&enrichSource=Y292ZXJQYWdlOzMxOTY2MjE0MjtBUzo1 Mzc5NDUxNzk0Nj 
M2ODBAMTUwNTI2NzUzMzQ0Mw\%3D\%3D\&el=1_x_2\&_esc=publicationCoverPd f. Acesso em 27 de outubro de 2020.

JOYE, C. R.; MOREIRA, M. M.; ROCHA, S. S. D. Educação a Distância ou Atividade Educacional Remota Emergencial: em busca do elo perdido da educação escolar em tempos de COVID-19. Research, Society and Development, v. 9, n. 7, 2020.

MOREIRA, J. A. M.; HENRIQUES, S.; BARROS, D. Transitando de um ensino remoto emergencial para uma educação digital em rede, em tempos de pandemia. Dialogia, São Paulo, n. 34, p. 351-364, jan./abr. 2020.

NASCIMENTO, P. M.; RAMOS, D. L.; MELO, A. A. S.; CASTIONI, R. Acesso domiciliar à internet e ensino remoto durante a pandemia. IPEA, Brasil, 2020.

OLIVEIRA, S. S.; SILVA, O. S. F.; SILVA, M. J. O. Educar na incerteza e na urgência: implicações do ensino remoto ao fazer docente e a reinvenção da sala de aula. Número Temático - vol. 10 n. 1 - 2020. Disponível em: < https://periodicos.set.edu.br/educacao/article/view/9239>. Acesso em $10 \mathrm{de}$ novembro de 2020.

SALMON, G. E-actividades. El factor clave para uan formación en línea activa. Barcelona: Editorial UOC, 2004.

SARAIVA, K.; TRAVERSINI, C.; LOKMANN, K. A educação em tempos de COVID-19: ensino remoto e exaustão docente. Práxis Educativa, Ponta Grossa, v. 15, e2016289, p. 1-24, 2020. Disponível em:

https://www.revistas2.uepg.br/index.php/praxiseducativa. Acesso em: 25 de outubro de 2020.

SILVA, J. B. A utilização da experimentação remota como suporte para ambientes colaborativos de aprendizagem. Florianópolis, 2006. Disponível em: $<$ https://repositorio.ufsc.br/handle/123456789/88357>. Acesso em 24 de outubro de 2020.

VALENTE, G. S. C.; MORAES, E. B.; SANCHEZ, M. C. O.; PACHECO, M. C. M. D. $O$ ensino remoto frente às exigências do contexto de pandemia: Reflexões sobre a prática docente. Research, Society and Development, v. 9, n. 9.

Disponível em: http://dx.doi.org/10.33448/rsd-v9i9.8153. Acesso em 23 de outubro de 2020. 